\title{
Is deep-sea species diversity really so high? Species diversity of the Norwegian continental shelf
}

\author{
John S. Gray \\ Department of Marine Zoology and Marine Chemistry, School of Biology, PB 1064, University of Oslo, N-0316 Oslo, Norway
}

\begin{abstract}
Sanders (1968; Am. Nat. 102: 243-281) showed that, contrary to general opinion at the time, the deep-sea had high species diversity when compared with estuarine and coastal areas. This paper stimulated a series of studies and theoretical arguments aimed at explaining why the deep-sea had such high diversity. It is now accepted that the deep-sea has high diversity and it has been suggested that in the deepsea there may be up to 10 million new species yet to be described (Grassle \& Maciolek 1992; Am. Nat. 139: 313-341). Surprisingly, however, there have not been any recent comparisons between the fauna of the deep-sea and shallower areas. Here I present data from a survey taken from the continental shelf of Norway which allows a quantitative comparison to be made with recent data from the deep-sea. Species diversity is very similar to that of the deep-sea and speciesarea curves have almost identical slopes. These data suggest that the Norwegian continental shelf has species diversity equal to that of the deep-sea and thus leads one to question the paradigm that the deep-sea has exceptionally high diversity.
\end{abstract}

KEY WORDS: Species diversity · Norwegian continental shelf

Based on semi-quantitative data obtained from a comparative study of the fauna of shallow estuaries, the Arabian Sea and the continental slope of the deepsea, Sanders (1968) first showed that the deep-sea had higher species diversity than expected. Since Sanders' work there have been a number of quantitative studies of the benthic fauna of the deep-sea (Grassle 1972, 1989, Hessler \& Jumars 1974, Jumars 1976, Gage 1979, Hecker \& Paul 1979, Rowe et al. 1982, Grassle \& Morse-Porteus 1987), which have confirmed Sanders' findings of high numbers of species in the deep-sea. However, all of these studies were of limited areas.

Recently, from extensive quantitative sampling of a $176 \mathrm{~km}$ transect, Grassle \& Maciolek (1992) found that the deep-sea benthic communities off the east coast of the USA had 'a remarkably high diversity'. From depths of between 1500 and 2100 m, a total of 798 spe- cies representing 171 families and 14 phyla was found from a total area sampled of $21 \mathrm{~m}^{2}$. Grassle \& Maciolek suggested that this number of species was especially high in the deep-sea in that their (unpublished) studies on George's Bank at $80 \mathrm{~m}$ depth had only 200 species. Poore \& Wilson (1993), however, reported that more than 700 infaunal species occur in Port Phillip Bay, Australia and that more than 800 species have been found from $10 \mathrm{~m}^{2}$ in Bass Strait, Australia, suggesting high diversity in shallow areas. They did not, however, give quantitative comparisons which could be used to relate to the deep-sea data of Grassle \& Maciolek.

Etter \& Grassle (1992) found, for the fauna of the deep-sea slope off the eastern United States, relationships between species diversity and depth and species diversity and sediment heterogeneity. They suggested that sediment particle size diversity has an important role in determining the number of species within a community and that bathymetric patterns are largely attributable to changes in sediment characteristics with depth. Thus if comparative studies are to be made, influences of depth and habitat heterogeneity on species diversity must be determined.

Here I present data from the Norwegian continental shelf which are analysed with methods as similar as possible to those used by Grassle \& Maciolek in order to compare, in a quantitative way, species diversity on the continental shelf with that of the deep-sea.

Methods. As part of the requirements for permission to explore for and exploit oil and gas reserves of the continental shelf of Norway, companies are required to do biological surveys of the sea-bed benthos every $3 \mathrm{yr}$ and to report this data to the Norwegian State Pollution Board (SFT). Some fields, such as Ekofisk, have been monitored since the $1970 \mathrm{~s}$. Within the last $5 \mathrm{yr}$ the collection, sorting and identification of samples has been subjected to careful quality control by an expert group 
(of which I am a member). Using the data from these surveys I have built up a reliable data base. The primary purpose of the data base is to give the State Pollution Board an objective overview of any negative effects on the coastal environment.

Samples were taken with a $0.1 \mathrm{~m}^{2}$ Van Veen grab with 5 replicates at each station (here pooled data for each station are used). Samples were washed through a $1 \mathrm{~mm}$ pore diameter sieve and the retained fauna preserved for later identification. Species identification was undertaken by a series of consultants using only an approved list of identification material. Only species that have been approved by the Riksmuseum Stockholm can be added to the list, thus synonyms and obvious misidentifications are weeded out (see Støvring 1994 for a complete list of the species found). Minor taxonomic groups, however, receive variable attention. In order to make this data as comparable as possible to that of Grassle \& Maciolek, faunal groups not properly sampled by the methods used, such as meiofaunal nematodes, Foraminifera, or inhabitants of hard substrata such as Porifera, Bryozoa and Cirrepedia, were not included. Likewise juveniles were excluded and unidentified species were only included if another species had been identified within the same genus. This rigorous treatment of the data reduced the total number of putative species by around 100. For each field the quality-controlled species list was subjected to multivariate analysis using standardised methods as in Gray et al. (1991). Uncontaminated stations were identified from such analyses and only data from these stations were used in this paper.

Following Sanders' pioneering study, diversity in the marine environment is usually expressed as a cumulative curve of species number plotted against the cumulative number of individuals. In order to present data directly comparable to that for the deep-sea, the number of species pooled over the 5 grab samples from an individual station was summed cumulatively over all stations from a given field, starting with the lowest station number. The cumulative number of species from the northernmost field was then used as the starting point for the first station of the next field moving south- wards. It was thus possible to obtain a north-to-south transect from the Heidrun field to the Tommeliten field in the North Sea, a distance of $1200 \mathrm{~km}$. Here, therefore, regional scales of diversity patterns are considered.

Sediment properties were measured on sub-samples taken from separate grabs and containing the surface $2 \mathrm{~cm}$. Median diameter (phi units) and sorting (as standard deviation in phi units) were calculated.

Results and discussion. The edge of the continental shelf is defined by Weyl (1970) as a region of rapid increase in depth over a short distance. Whilst most continental shelves have a depth limit of $200 \mathrm{~m}$ this is not so for Norway where the continental shelf edge occurs at $500 \mathrm{~m}$. Near the coast there are deep areas in the Skagerrak and Norwegian trench of over $600 \mathrm{~m}$. Thus the data here from 70 to $300 \mathrm{~m}$ are well within the limits of the Norwegian continental shelf. All the oil exploration in Norway, from where these data arises, is described as occurring on the Norwegian continental shelf.

Table 1 shows a summary of the data for a north-tosouth transect across the Norwegian continental shelf.

Cumulative species number was plotted against cumulative number of individuals and cumulative area (Fig. 1). For the Norwegian transect a total of 39582 individuals and 620 species were found. Grassle \& Maciolek's data for a similar plot (their Fig. 11) show around 625 species from 65000 individuals. (This plot excludes 3 stations at $2100 \mathrm{~m}$ depth, hence the lower number of species and individuals compared with the whole transect; 798 species and 91000 individuals). Thus the Norwegian shelf data has a similar number of species from a lower number of individuals. Using the rarefaction curve given by Grassle \& Maciolek, for 40000 individuals only approximately 550 species were found in the deep-sea, considerably less than the Norwegian shelf's 620 species.

But how valid is such a comparison? Grassle \& Maciolek sampled only $21 \mathrm{~m}^{2}$ compared with the $50 \mathrm{~m}^{2}$ sampled along the Norwegian shelf transect. A larger sampled area (Norwegian shelf) would be expected to give more individuals and species. Yet Table 1 shows

Table 1. Location of oil fields on the Norwegian continental shelf and basic data

\begin{tabular}{|lcccccr|}
\hline Field & Lat., Long. & Depth $(\mathrm{m})$ & Type of sand & $\begin{array}{c}\text { Area sampled } \\
\left(\mathrm{m}^{2}\right)\end{array}$ & $\begin{array}{c}\text { Total no. } \\
\text { of spp. }\end{array}$ & $\begin{array}{c}\text { Total no. } \\
\text { of ind. }\end{array}$ \\
\hline Heidrun & $65^{\circ} 20^{\prime} \mathrm{N}, 07^{\circ} 18^{\prime} \mathrm{E}$ & 305 & Fine & 13 & 166 & 5746 \\
Snorre & $61^{\circ} 7^{\prime} \mathrm{N}, 02^{\circ} 08^{\prime} \mathrm{E}$ & 300 & Muddy & 20 & 311 & 15053 \\
Gullfaks & $61^{\circ} 14^{\prime} \mathrm{N}, 02^{\circ} 14^{\prime} \mathrm{E}$ & 210 & Medium-coarse & 7.0 & 221 & 10917 \\
Ekofisk & $56^{\circ} 32^{\prime} \mathrm{N}, 03^{\circ} 15^{\prime} \mathrm{E}$ & 72 & Fine-medium & 4.5 & 122 & 2236 \\
Tommeliten & $56^{\circ} 29^{\prime} \mathrm{N}, 02^{\circ} 58^{\prime} \mathrm{E}$ & 70 & Fine & 5.5 & 162 & 5630 \\
Total & & & & 50.0 & 620 & 39582 \\
\hline
\end{tabular}



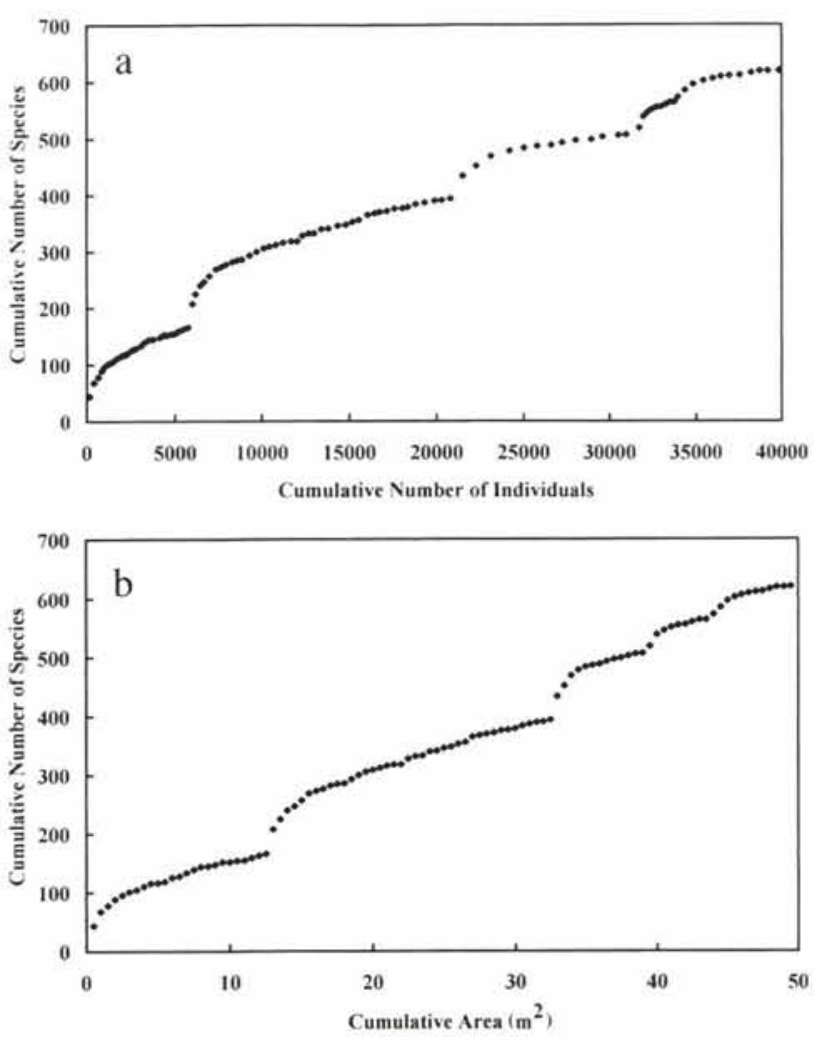

Fig. 1. Plots of individual samples combined in an ordered sequence from north to south starting with lowest station number within each field. (a) Species against cumulative number of individuals; (b) species against cumulative area $\left(\mathrm{m}^{2}\right)$

that the number of individuals in the Norwegian data is lower than that in the deep-sea. The comparison used here is not based on cumulative number of species per area but the traditional method used in marine biology, that of cumulative number of species against cumulative number of individuals. The Norwegian data has over 70 more species for comparable numbers of individuals than the deep-sea off the east coast of the USA.

However, the greatest problem in making this comparison is whether it is admissible to compare deep-sea samples obtained on a $0.3 \mathrm{~mm}$ sieve with the shelf samples obtained on a $1 \mathrm{~mm}$ sieve. Use of any fixed sieve size will lead to selection of a certain proportion of the species and individuals present. The exact sieve size used is usually a compromise between the practical difficulties of sorting fauna from sediments and yet retaining a representative number of species and individuals. The assumption made here is that the 2 different sieve sizes are sampling representative proportions of the species represented within the deep-sea and continental shelf areas studied.

The deep-sea fauna is on average smaller than the shelf fauna (see discussion in Gage \& Tyler 1991), hence a finer mesh sieve $(0.25$ or $0.3 \mathrm{~mm})$ is used as a 'standard' size for obtaining representative samples of the deep-sea fauna. For example, for the deep-sea Dinet et al. (1985) defined the deep-sea macrofauna sensuo stricto as excluding nematodes, copepods, ostracods etc. but sensuo lato as including everything retained on a $0.25 \mathrm{~mm}$ sieve. Trials on the Norwegian continental shelf showed that use of a $0.5 \mathrm{~mm}$ sieve size was unworkable as much sediment was retained which led to sorting difficulties. Thus a $1 \mathrm{~mm}$ sieve size was standardised in a set of guidelines (SFT 1990) since it was agreed by the expert panel setting the guidelines that this size gave a representative proportion of both species and individuals.

I believe, therefore, that the fauna retained on the 2 sieve sizes give approximately comparable proportions of species and individuals for their respective areas and that it is valid to make general comparisons of cumulative number of species against cumulative number of individuals at 2 regional scales $(176 \mathrm{~km}$ in the deep-sea off the U.S. east coast with $1200 \mathrm{~km}$ along the Norwegian continental shelf). The data show that diversity values are of comparable magnitude and not 2 to 3 times higher in the deep-sea as Sanders' data showed and on which the paradigm of high deep-sea diversity was built.

It might be argued that along a transect of $1200 \mathrm{~km}$ one is sampling a variety of different habitats whereas the deep-sea slope sediment was relatively uniform (not given in Grassle \& Makiolek, but described as sandy mud to clayey muds in an unpublished report on the same data). Although Table 1 shows that both depth and type of sediment varied across the Norwegian shelf, no relationship was found between either number of species and depth or number of species and sediment properties (Fig. 2). Furthermore, since the diversity of deep-sea fauna is known to vary with sediment properties (Etter \& Grassle 1992) it may be argued that a difference between sandy mud and clayey mud is as significant for deep-sea fauna as the variations in sediment properties measured on the Norwegian shelf. Thus the comparison made above between number of species per 40000 individuals seems valid and the shelf has a higher diversity than the deep-sea, as was postulated by Osman \& Whitlach (1978). Poore \& Wilson's (1993) data showing that in Australia 800 species have been recorded from just $10 \mathrm{~m}^{2}$ of sediment in Bass Strait and that 700 species occur in Port Phillip Bay sediments support the contention that the shelf has equal, if not higher, diversity than the deep-sea.

The finding that species number does not vary with either depth or sediment properties on the Norwegian shelf is in marked contrast to that of the deep-sea (Etter \& Grassle 1992), where there was a maximum 

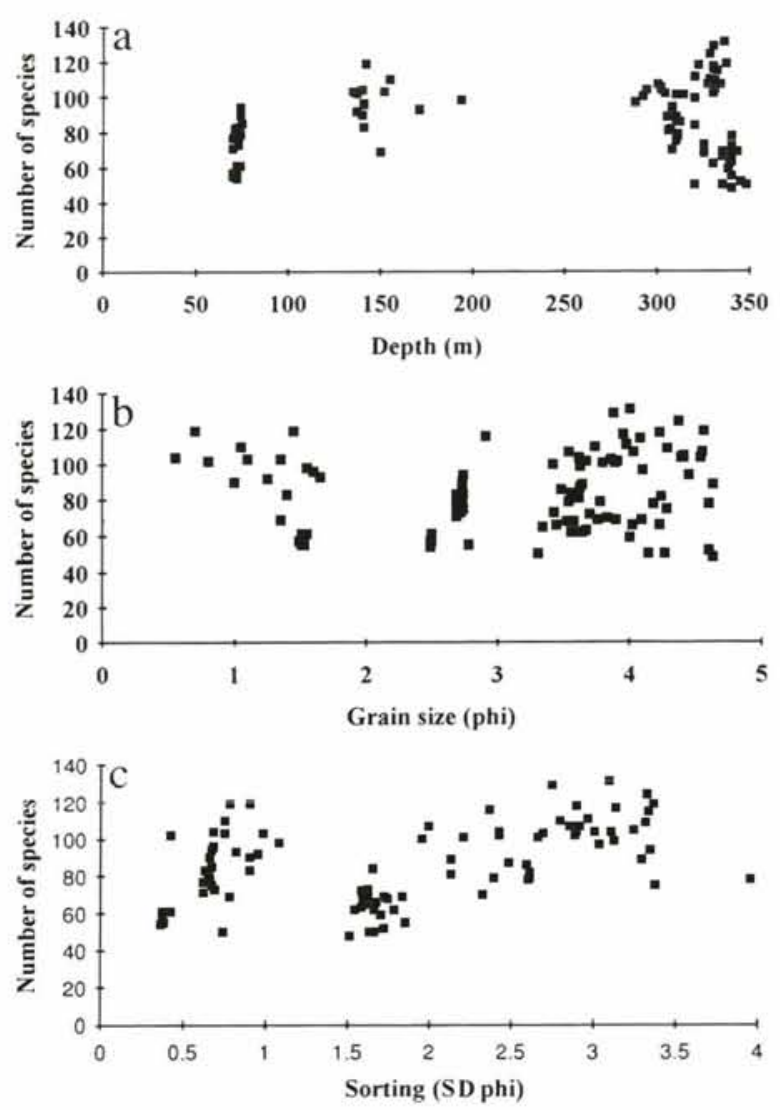

Fig. 2. Plots of species number against depth and sediment properties: (a) depth, (b) grain size as median particle diameter and (c) sorting coefficient

diversity at intermediate depth of $1300 \mathrm{~m}$ (within a range from 500 to $2000 \mathrm{~m}$ ) and diversity increased linearly with the silt diversity of the sediment. It seems likely that the deep-sea fauna partition the habitat more finely than the fauna of the shelf. Smallscale heterogeneity in the deep-sea is produced by a variety of factors such as the activity of organisms (Jumars 1976, Aller \& Aller 1986, Smith 1986, Smith et al. 1986) and other factors such as sedimenting phytoplankton (Billett et al. 1983) and its effect on colonisation processes (Snelgrove et al. 1992), seaweed and salp blooms (Grassle \& Morse-Porteus 1987) and wood (Turner 1973, 1977). These structures persist for long periods in the deep-sea and thus organisms have become adapted to the fine-scale heterogeneity. On the continental shelf, physical disturbance is frequent and organisms are likely to show broader-scale relationships to environmental factors than the deepsea.

In an intertidal area, relationships also have been found between species number and sediment properties, (Whitlach 1977, 1981). However, only a maximum of 18 species were found which is not comparable to the hundreds of species analysed in this study.
Grassle \& Maciolek showed that dominance along the deep-sea transect was extremely low, with a maximum of $7.1 \%$. Dominance patterns were calculated for the cumulative data for the Norwegian transect (Table 2).

Table 2 shows that dominance on the Norwegian shelf, pooled across samples, has a maximum of only $7.06 \%$ and the tenth most dominant species comprised only $1.65 \%$. The species of Aetea, Aricidea and Thyasira were not determined and thus dominance may be even lower. These data are entirely consistent with that for the deep-sea slope where the most dominant species comprised $7.1 \%$ and the tenth dominant $2.1 \%$. Thus there is no difference between pooled dominance in the deep-sea and shelf.

This result may simply reflect that fact that one is pooling over many samples. Dominance within 1 site was much higher (occasionally up to $30 \%$ ), within fields it was up to $23.5 \%$ at Gullfaks, and it was only over the pooled data over all fields that it dropped to $7 \%$, reflecting the fact that different species dominate in different areas.

Finally, the high diversity shown on the Norwegian continental shelf is in marked contrast to the extremely low diversity shown in the deep-sea area of the Norwegian Sea (Rex et al. 1993). In this latter study the latitudinal gradient in the deep-sea fauna, showing an increase from the Arctic to the tropics, was largely determined by the low diversity found in the Norwegian Sea as the other data had high variance and showed no distinct pattern.

The data presented here, showing high diversity on the Norwegian continental shelf, suggest that for continental shelf fauna the pole-to-tropic gradient is likely to be at best weak if detectable at all. However, more data are urgently needed to test this hypothesis and to test the postulate here that continental shelf diversity can be as high as that of the deep-sea.

Perhaps more importantly, if the Norwegian shelf data are representative for many continental shelf areas,

Table 2. Dominance patterns across whole data set

\begin{tabular}{|lc|}
\hline Species & $\%$ Dominance \\
\hline Ophiura affinis & 7.06 \\
Onchnesoma steenstrupi & 5.06 \\
Aetea spp. & 3.52 \\
Aricidea spp. & 3.38 \\
Paramphinome jeffreysi & 2.81 \\
Thyasira spp. & 2.67 \\
Goniada maculata & 2.34 \\
Eudorellopsis deformis & 2.09 \\
Chaetozone setosa & 1.97 \\
Amphiura filiformis & 1.65 \\
\hline
\end{tabular}


then, in terms of the Biodiversity Convention agreed at the UNCED meeting in Rio de Janeiro, more attention needs to be given to the biodiversity of coastal areas since these, rather than the deep-sea, are subject to huge direct and indirect changes induced by man.

\section{LITERATURE CITED}

Aller, J. Y., Aller, R.C. (1986). Evidence for localised enhancement of biological activity associated with tube and burrow structures in deep-sea sediments at the HEBBLE site, western North Atlantic. Deep Sea Res. 33: 755-790

Billett, D. S. M., Lampitt, R., Rice, A. L., Mantoura, R. F. C. (1993). Seasonal sedimentation of phytoplankton to the deep-sea benthos. Nature 302: $520-522$

Dinet, A., Desbruyères, D., Khripounoff, A. (1985). Abondance des peuplements macro- et meio-benthiques: répartition et stratégie d'échantillonage. In: Laubier, L., Monniot C. (eds.) Peuplements profonds du golfe du Gascogne. Institut Français de Recherche pour l'Exploitation de la Mer, Brest, p. 121-142

Etter, R. J., Grassle, J. F. (1992). Patterns of species diversity in the deep-sea as a function of sediment particle size diversity. Nature 360: $576-578$

Gage, J. D. (1979). Macrobenthic community structure in the Rockall Trough. Ambio Special report 6: 43-46

Gage, J. D., Tyler, P. A. (1991). Deep sea biology. Cambridge University Press, Cambridge

Grassle, J. F. (1972). Species diversity, genetic variability and environmental uncertainty. In: Battaglia, B. (ed.) Proc. 5th European Marine Biology Symposium. Piccin, Padua, p. $19-26$

Grassle, J. F. (1989). Species diversity in deep-sea communities. Trends Ecol. Evol. 4: 12-15

Grassle, J. F., Maciolek, N. J. (1992). Deep-sea species richness: regional and local diversity estimates from quantitative bottom samples. Am. Nat. 139: 313-341

Grassle, J. F., Morse-Porteus, L. (1987). Macrofaunal colonization of disturbed deep-sea environments and the structure of deep-sea benthic communities. Deep Sea Res. 34: 1911-1950

Gray, J. S., Clarke, K. R. Warwick, R. M., Hobbs, G. (1991). Detection of initial effects of pollution on marine benthos: an example from the Ekofisk and Eldfisk oilfields, North Sea. Mar. Ecol. Prog. Ser. 66: 285-299

Hecker, B., Paul, A. Z. (1979). Abyssal community structure of the benthic infauna of the eastern equatorial Pacific: DOMES sites A, B and C. In: Bischoff, J. F. Peper, D. Z. (eds.) Marine geology and oceanography of the Pacific Manganese nodule Province, Marine science 9. Plenum,

This note was submitted to the editor
New York, p. 287-308

Hessler, R. R., Jumars, P. A. (1974). Abyssal community analysis from replicate box cores in the central north Pacific. Deep Sea Res: 21: 185-209

Jumars, P. A. (1976). Deep-sea species diversity: does it have a characteristic scale? J. mar. Res. 34: 217-246

Osman, R. W., Whitlach, R. B. (1978). Patterns of species diversity: fact or artefact? Paleobiology 4: 41-54

Poore, G. C. B., Wilson, G. D. F. (1993). Marine species richness. Nature 361: 597-598

Rex, M. A. Stuart, C. T., Hessler, R. R., Allen, J, R., Sanders, H. L., Wilson, G. D. F. (1993). Global-scale latitudinal patterns of species diversity in the deep-sea benthos. Nature 365: 636-639

Rowe, G. T., Polloni, P. T., Haedrich, R. L. (1982). The deepsea macrobenthos on the continental margin of the Northwest Atlantic Ocean. Deep Sea Res. 29: 257-278

Sanders, H. L. (1968). Marine benthic diversity: a comparative study. Am. Nat. 102: 243-281

SFT (1990). Manual for overvåkingsundersøkelser rundt petroleumsinstallasjoner i norske havomrăder. Satens forurensningstilsyn, Oslo, 90:01, 29 pp.

Smith, C. R., Jumars, R. L., DeMasters, D. J. (1986). In situ studies of megafaunal mounds indicate rapid sediment turnover and community response at the deep-sea floor. Nature 323: 251-253

Smith, C. R. (1986). Nekton falls, low-intensity disturbance and community structure of infaunal benthos in the deepsea. J. mar. Res. 44: 567-600

Snelgrove, P. V. R., Grassle, J. F., Petrecca, R. F. (1992). The role of food patches in maintaining high deep-sea diversity: field experiments with hydrodynamically unbiased colonization trays. Limnol. Oceanogr. 37: 1543-1550

Støvring, M. (1994). North Sea zoobenthos reported from the vicinity of oil platforms. In: Zetterberg, G. (ed.) 1994-term, List ZB, North Sea Zoobenthos, Version 930309-GUZ Environmental Data Standardisation, Term-List 2. Swedish Museum of Natural History, Stockholm

Turner, R. (1973). Wood-boring bivalves, opportunistic species in the deep-sea. Science 180: 1377-1379

Turner, R. (1977). Wood, mollusks, and deep-sea food chains. Bull. Am. Malac. Un. 1977: 13-19

Weyl, P. K. (1970). Oceanography: an introduction to the marine environment. John Wiley, New York

Whitlach, R. B. (1977). Seasonal changes in the community structure of the macrobenthos inhabiting the intertidal sand and mud flats of Barnstable Harbour, Massachusetts. Biol. Bull. 152: 275-294

Whitlach, R. B. (1981). Animal-sediment relationships in intertidal marine benthic habitats: some determinants of deposit-feeding species diversity. J. exp. mar. Biol. Ecol. 53: $31-45$

Manuscript first received: March 2, 1994

Revised version accepted: June 13, 1994 